ORIGINAL ARTICLE

\title{
Medical experience of a university hospital in Turkey after the 1999 Marmara earthquake
}

\author{
M Bulut, R Fedakar, S Akkose, S Akgoz, H Ozguc, R Tokyay
}

Emerg Med J 2005;22:494-498. doi: 10.1136/emj.2004.016295

\begin{abstract}
See end of article for authors' affiliations

.....................

Correspondence to: Dr M Bulut, Department of Emergency Medicine, Uludag University Medical School, 16059 Bursa Turkey; mbulut94@yahoo. com

Accepted for publication 17 June 2004
\end{abstract}

\begin{abstract}
Objectives: This study aimed to provide an overview of morbidity and mortality among patients admitted to the Hospital of the Medicine Faculty of Uludag University, Bursa, Turkey, after the 1999 Marmara earthquake.

Methods: Retrospective analysis of the medical records of 645 earthquake victims. Patients' demographic data, diagnosis, dispositions, and prognosis were reviewed.

Results: A total of 330 patients with earthquake related injuries and illness admitted to our hospital were included and divided into three main groups: crush syndrome $(n=110)$, vital organ injuries $(n=57)$, and non-traumatic but earthquake related illness $(n=55)$. Seventy seven per cent of patients were hospitalised during the first three days after the earthquake. The rate of mortality associated with the crush syndrome, vital organ injury, and non-traumatic medical problems was $21 \%(23 / 110), 17.5 \%$ (10/57), and $9 \%$ (5) 55), respectively. The overall mortality rate was $8 \%(50 / 645)$.

Conclusions: In the first 24-48 hours after a major earthquake, hospital emergency departments are flooded with large numbers of patients. Among this patient load, those patients with crush syndrome or vital organ injuries are particularly at risk. Proper triage and prompt treatment of these seriously injured earthquake victims may decrease morbidity and mortality. It is hoped that this review of the challenges met after the Marmara earthquake and the lessons learned will be of use to emergency department physicians as well as hospital emergency planners in preparing for future natural disasters.
\end{abstract}

\section{METHODS}

We retrospectively reviewed the medical records of patients with earthquake related injuries and diseases hospitalised between 17 August and 4 October 1999. We recorded the patients' demographic data, complaints, diagnoses, injury types, dispositions (including admission, discharge, and transfer), prognoses, presence of crush syndrome and/or acute renal failure (ARF), number of dialyses, and surgical procedures undertaken, such as fasciotomies and amputations.

Crush syndrome was defined as presence of crush injuries, oedema, and/or neurological disturbances (including motor and/or sensory deficits at the injury sites), and myoglobinuria (or dark brown coloured urine indicating the presence of myoglobin) with or without acute renal failure. Acute gastroenteritis, hepatitis, psychological symptoms, and exacerbations of pre-existing medical conditions, such as diabetes mellitus and arterial hypertension, were considered as earthquake related illnesses, and we reviewed age, sex, diagnosis, mortality and causes of mortality in these cases.

We used SPSS for Windows version 10.0 for the statistical analysis. When analysing the factors that we considered had an effect on mortality among the trauma patients (such as age, sex, presence of crush syndrome and/or ARF, etc.), those cases in which even one of these factors was missing were not included in the statistical evaluation. In this paper, categorical variables are presented as frequencies and percentages, and continuous variables are presented as average, standard deviation, and median values. We used Pearson's $\chi^{2}$ test, Fisher's exact test and the KolmogorovSmirnov test for comparing intragroup distributions of categorical variables, and the Mann-Whitney and KruskalWallis tests for comparing intergroup distributions of continuous variables. For determination of the factors that affected mortality in trauma cases we used univariate and 
multivariate (forward stepwise) logistic regression analyses. A p value $<0.05$ was considered as significant.

\section{RESULTS}

A total of 645 patients with earthquake related injuries were admitted to our ED in the study period. The medical records of 58 patients were insufficient to determine the diagnosis and the injury site. The rate of hospitalisation was 52\% (330/ 645 patients). The rate of ED discharge was 34\% $(n=220)$ and transfer to another hospital $13 \%(n=87)$, and ED mortality was $1 \%(n=8)$. Our inpatient mortality was $15 \%$ $(\mathrm{n}=50)$.

The distribution of the 645 patients according to their time of presentation is shown in fig 1 . A total of $42 \%(n=271)$ were admitted on the first day and $77 \%(n=498)$ in the first three days. Of the patients admitted on the first day, $60 \%$ presented with earthquake related trauma. The number of non-trauma patients admitted increased substantially during the subsequent days. Seven patients died in the ED on the first day of the earthquake and one on the second day. The mean age of the hospitalised patients (48\% male and 52\% female) was 26.1 years (range 0-79 years).

\section{Clinical characteristics of 263 patients with earthquake related trauma}

A total of 263 patients $(46.3 \%(n=122)$ male and $53.6 \%$ $(\mathrm{n}=141)$ female; mean (SD) age 32.4 (16.9) years, median 30 , range 3.5 months to 77 years) with earthquake related trauma were included in the statistical analysis. The most frequently occurring injuries among the hospitalised trauma patients were injuries to the extremities (fractures, dislocations, soft tissue injuries) (66.6\%), followed by spinal (9.5\%), chest $(7.5 \%)$, abdominal $(7.1 \%)$, cranial $(6.8 \%)$, and pelvic $(4.5 \%)$ injuries (fig 2). Among the patients with crush injuries, 110 patients were diagnosed as having crush syndrome.

Of the 176 patients with injured extremities, 56 had lower extremity fractures $(31.8 \%), 13$ had upper extremity fractures $(7.3 \%)$, and 3 had dislocations (1.7\%; 2 pelvic and 1 knee cap). Mortality among the 176 patients with injured extremities was $10.7 \%(n=19)$. Mortality rate in the spine $(\mathrm{n}=25)$ and pelvic $(\mathrm{n}=12)$ fracture groups was $4 \%$ and $16.6 \%$, respectively.

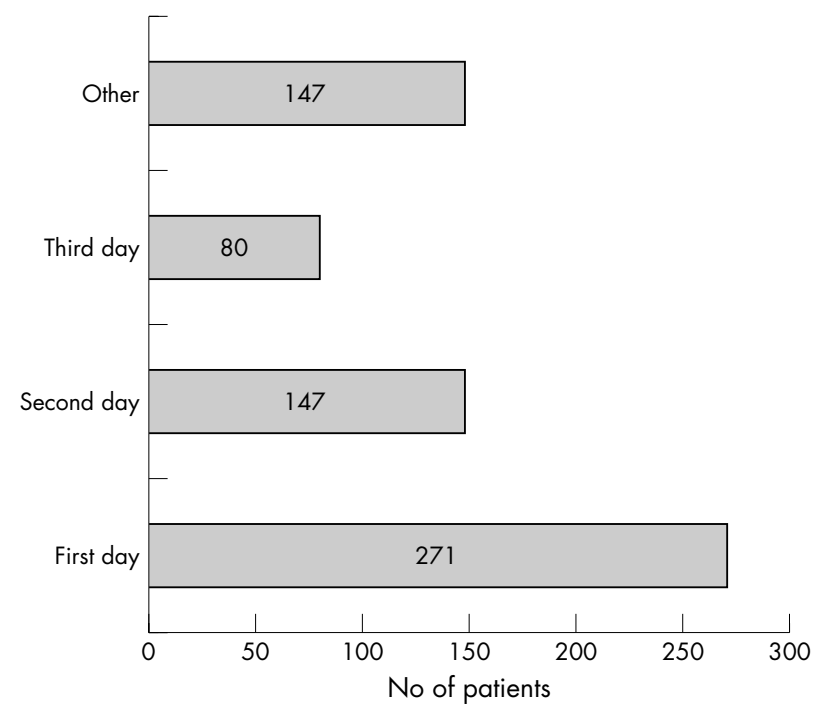

Figure 1 Distribution of 645 patients with earthquake related trauma admitted to the Emergency Department on the basis of their date of admission.

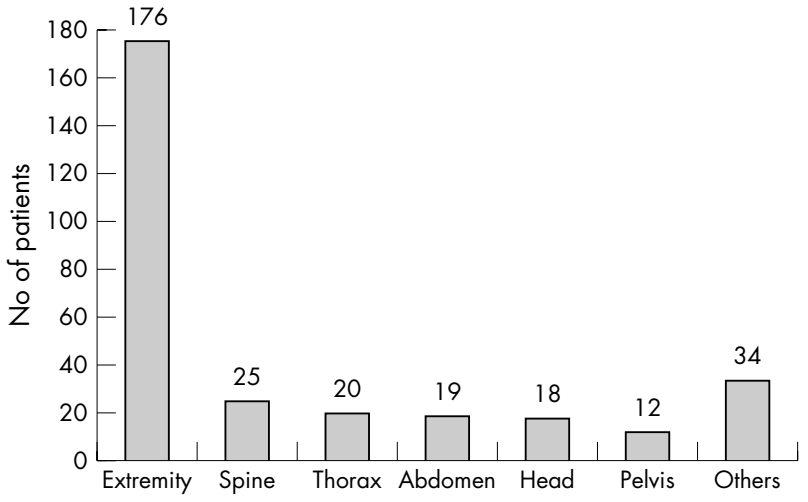

Figure 2 Distribution of hospitalised trauma patients according to their injuries.

A total of 108 patients with chest injuries were admitted. Of these, 89 were transferred to another hospital after initial evaluation in our ED. A chest tube was inserted in 34/54 hospitalised patients in the ED. The mortality rate among the hospitalised chest trauma patients was $10 \%(n=2)$. The cause of death of one of these patients, a 15 year old girl, was "crush syndrome + ARF + sepsis" and of the other, a 65 year old man, was bilateral pulmonary contusion and acute myocardial infarction.

Nineteen patients with abdominal injuries were admitted, of whom nine underwent laparotomy. The mortality rate was $36.8 \%$ (7/19). According to the medical records of these patients, ARF, sepsis, and multiple organ failure were the main causes of death. Three patients with signs and symptoms of acute abdomen were successfully treated nonoperatively. There were 18 patients with head injuries but most of these injuries were minor; one patient with a Glasgow Coma Score of 9 died (5.5\%).

Among the hospitalised patients $64.5 \%(\mathrm{n}=158)$ sustained injuries in only one system (group A), whereas $12.7 \%$ $(\mathrm{n}=31)$ had multiple system trauma (group B) and $23 \%$ $(\mathrm{n}=56)$ had trauma accompanied by the crush syndrome (group C); the mortality rate in the three groups was $10 \%$, $5 \%$, and $85 \%$, respectively. There were no significant differences between the groups in terms of age and sex (Kruskal-Wallis test, Pearson $\chi^{2}$ test, $\mathrm{p}>0.05$ ). Compared with groups $\mathrm{A}$ and $\mathrm{B}$, mortality was higher in group $\mathrm{C}$ (Kolmogorov-Smirnov test, $\mathrm{p}<0.001$ ), and there was no significant difference between groups A and B (table 1). On univariate logistic regression analysis, we found that the odds ratio of death in group C was increased 33.9-fold compared with group A (OR $=33.9 \%$; $95 \%$ CI 7.5 to 153.4$)$ and 2.6-fold compared with group B (OR $=2.6 \%$; 95\% CI 0.2 to 29.6 ). To determine the factors influencing mortality, age, sex, and the trauma group were taken as independent variables in the multivariate logistic regression analysis. Age and sex had no significant influence on mortality, but in group $\mathrm{C}$, the odds ratio of death was increased 21.7-fold when compared with group A (OR $=21.7 \%$; $95 \%$ C I 4.7 to 101.0).

\section{Surgical treatment}

The commonest surgical procedure undergone by the patients with earthquake related injuries was fasciotomy $(n=130)$, followed by tube thoracostomy $(\mathrm{n}=34)$, and open reduction plus internal fixation $(n=28)$. A total of 24 extremities of 18 patients were amputated, of which none was a primary amputation. Nine patients underwent laparotomy and seven had external fixation. 
Table 1 Statistical evaluation of the factors affecting mortality in the hospitalised trauma patients

\begin{tabular}{|c|c|c|c|}
\hline Variables & Dead & Alive & $\mathrm{p}$ value \\
\hline \multicolumn{4}{|l|}{ Age in years } \\
\hline Mean (SD) & $33.9(20.3)$ & $32.3(16.6)$ & \multirow{3}{*}{$p>0.05^{*}$} \\
\hline Median & 28.0 & 30.0 & \\
\hline Range (n) & $\begin{array}{l}12.0-66.0 \\
(16)\end{array}$ & $\begin{array}{l}1.0-77.0 \\
(219)\end{array}$ & \\
\hline \multicolumn{4}{|l|}{ Sex } \\
\hline Male $(n=120)$ & 11 & 109 & \multirow{2}{*}{$p>0.05 t$} \\
\hline Female $(n=141)$ & 16 & 125 & \\
\hline \multicolumn{4}{|l|}{ Trauma groups } \\
\hline Group A ( $n=158)$ & 2 & 156 & \multirow{3}{*}{$\mathrm{p}<0.001 \ddagger$} \\
\hline Group B $(n=31)$ & $\overline{1}$ & 30 & \\
\hline Group $C(n=56)$ & 17 & 39 & \\
\hline \multicolumn{4}{|c|}{$\begin{array}{l}\text { * Mann-Whitney test. } \\
\text { †Pearson's } \chi^{2} \text { test. } \\
\text { †Kolmogorov-Smirnov test } \\
\text { †Group A: patients with single system trauma; group B: patients with } \\
\text { multiple system trauma; group C: patients with crush syndrome and/or } \\
\text { acute renal failure and/or undergoing dialysis }\end{array}$} \\
\hline
\end{tabular}

\section{Patients with crush syndrome}

Of 110 patients with crush syndrome 60 required haemodialysis $(54.5 \%)$. The overall mortality among these patients was $21 \%(n=23)$. In the haemodialysis group the mortality was $35 \%(21 / 60)$. ARF, sepsis, and dialysis complications were the main causes of death $(n=21$; fig 3$)$. The remaining two patients died of haemorrhagic shock. The injuries sustained by the patients with crush syndrome patients by site are given in table 2 .

\section{Infections in the hospitalised patients}

Of 330 hospitalised patients, 295 were screened daily for infectious complications. Infections were documented in 76 cases $(25.8 \%)$ according to the Centers for Disease Control diagnostic criteria of hospital infections. Deep surgical infection was the commonest type of infection (33\%), and bacteraemia occurred in $20 \%$ of cases. The most frequently isolated microorganisms were Pseudomonas aeruginosa, Acinetobacter baumannii, methicillin resistant Staphylococcus aureus, and Candida spp. Mortality among in the patients screened by the hospital infection team was $10.8 \%(\mathrm{n}=32$ / 295); 19 deaths were due to infectious complications. The frequency of infectious complications was highest at the end of the first week after the earthquake. All patients received tetanus prophylaxis. There were no cases of gas gangrene or tetanus.

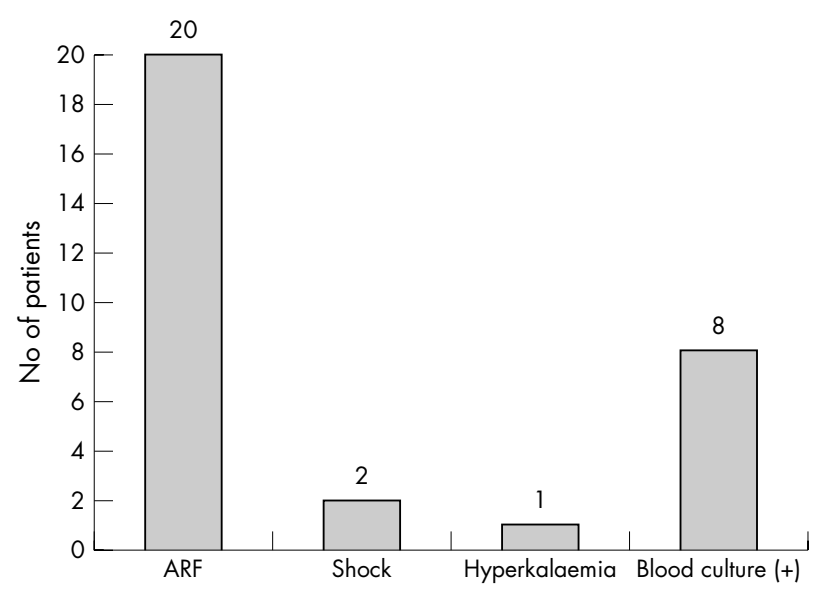

Figure 3 Causes of mortality among the patients with crush syndrome.
Table 2 Distribution of patients with crush syndrome according to the site of injury

\begin{tabular}{lc}
\hline Site of injury & No (\%) of patients \\
\hline One extremity & $47(42)$ \\
Two extremities & $33(30)$ \\
Three extremities & $3(3)$ \\
Four extremities & $2(2)$ \\
Thoracic injury & $1(1)$ \\
Multiple injuries & $24(21)$ \\
Total & $110(100)$ \\
\hline
\end{tabular}

\section{Clinical characteristics of the hospitalised non-trauma patients}

Fifty five patients $(16.6 \% ; 58 \%(n=32)$ males, $42 \%(n=23)$ females; mean age 32.7 years) were hospitalised for nonearthquake related causes. A quarter of these were admitted within the first three days of the earthquake. Acute coronary syndrome was the commonest diagnosis followed by paediatric (premature birth, meningitis, gastroenteritis, etc.) and neurological diseases. Mortality rate in this group was $9 \%$ $(n=5)$ and the causes of death were cerebral haemorrhage $(n=2)$, myocardial infarction $(n=2)$, and occlusive cerebrovascular disease $(\mathrm{n}=1)$.

\section{DISCUSSION}

During the past 20 years, natural disasters have claimed more than three million lives worldwide, affected at least 800 million people, and resulted in property damage exceeding US\$500 billion. ${ }^{7}$ In respect of losses of life and assets, earthquakes are the most harmful natural disasters. ${ }^{45}$ The 1976, the Tangshan earthquake in China caused more than 240000 deaths and 165000 injuries, and the 1985 Mexico City earthquake resulted in more than 7000 deaths. ${ }^{4589}$ In 1990, another devastating earthquake claimed the lives of 50000 people in Iran. According to the official records, the Marmara earthquake-one of the biggest natural disasters of the past decade-killed 17480 people and injured 43953. Natural disasters, especially earthquakes, are an important problem for Turkey.

A report on the 1989 Loma Prieta earthquake in California was the first to be based on emergency department census data, but we did not learn much from it because of the low casualty rate ( 1.3 deaths per 100000 population). ${ }^{10}$ The 1995 Hanshin-Awaji earthquake in Japan provided us with more detailed medical data. The present study aimed to provide further medical data on the patients admitted to our hospital following the Marmara earthquake and compare these data with those in the literature. We also wanted to share our ED experience during the period of the post-earthquake patient influx for better disaster preparedness in the future.

Following the Marmara earthquake, 645 patients were admitted to the ED and most of these presented within the first 12 hours. Initially, communication between our hospital and the field, and obtaining information about the severity of the catastrophe, was not possible. There were difficulties in keeping medical records of the patients presenting to our ED in the rush phase, especially within the initial several hours of the disaster, due to lack of knowledge about the patient load and severity of the injuries beforehand. However, an ED team was quickly organised and one ED nurse and one medical secretary were assigned to keeping medical records and patient census.

In a study following the Loma Prieta earthquake, Haynes et $a l^{11}$ reported that keeping medical records in hospitals receiving excessive numbers of victims was difficult and records of some patients were not kept at all. Other studies ${ }^{4}$ 
have also underlined the difficulty of keeping records in similar situations. In another study associated with the Loma Prieta earthquake, Martchenke et al ${ }^{12}$ stated that the most significant problem has been the lack of communication both within the hospital and between the hospital and other institutions. As cited by Chen et al, ${ }^{13}$ Thiel et al reported that following a devastating earthquake with large numbers of casualties, the greatest demand for medical attention occurs during the initial 24-48 hour period after the disaster. Likewise, Chen et al ${ }^{13}$ reported that in the 1999 Taiwan earthquake, $66.2 \%$ of patients arrived on the first day. In our study, $42 \%$ of the patients were admitted on the first day and $60 \%$ of these had earthquake related trauma.

Approximately five to six hours following the earthquake, an excessive number of medical personnel crowded the ED causing substantial disorganisation and problems in the coordination of care of the patients in the ED. This chaos was overcome by reorganising the triage process and assigning two physicians and two nurses to each emergency bed. The drawbacks of large numbers of medical personnel trying to provide care for victims of disaster have also been pointed out by Klein et al. ${ }^{14}$ They described a similar scene of inadequate triage and disorganised care after a plane accident in Dallas, $\mathrm{TX}$, although the scale of the incident was much smaller.

Natural disasters, especially earthquakes, result in many health problems all over the world, of which crush syndrome is one of the most commonly encountered clinical entities. ${ }^{15}$ During the last quarter of the twentieth century, devastating earthquakes have resulted in large numbers of crush syndrome cases: 600 cases were reported after the 1988 Armenian earthquake ${ }^{16}$ and 372 after the 1995 HanshinAwaji earthquake. ${ }^{17}$ In our study, 110 patients had crush syndrome $(33 \%)$, the highest number for an injury among the entire hospitalised patient population. Mortality among the patients with crush syndrome following the HanshinAwaji earthquake was reported as being $13.4 \%$, $^{18}{ }^{19}$ whereas in our study, it was $21 \%$. Although the discrepancy between the two rates is not pronounced, the difference may be due to our excessive use of fasciotomy instead of conservative treatment (or primary amputation in the severe cases). Consequently, our rate of deep surgical infections was high $(33 \%)$ and we lost many patients due to sepsis. In our study, primary amputation was not carried out in any of the patients but $16.3 \%$ of the 110 crush syndrome patients underwent secondary amputation. Following the HanshinAwaji earthquake primary amputation was done in six patients and fasciotomy in 70 of the 317 patients. ${ }^{15}$ An associated injury was present in $31 \%$ of the 372 crush syndrome patients after the Hanshin-Awaji earthquake ${ }^{17}$ whereas this figure was $22.7 \%(25 / 110)$ in our study.

In Tanaka et al' ${ }^{18}$ study of patients injured in the HanshinAwaji earthquake, fractures constituted $54.8 \%$ of all the injuries. Extremity fractures were the commonest (37.2\%). Likewise, Peak-Asa et al, in their study analysing hospitalised patients after the 1994 Northridge earthquake, reported that extremity injuries were the commonest $(72.4 \%)$, followed by spinal injuries (13\%). Similar high percentages of extremity injuries have also been reported in studies on the 1988 Armenian $^{18}$ and the Loma Prieta ${ }^{19}$ earthquakes. In our hospitalised trauma patients also, injuries to the extremities were the commonest $(66.6 \%)$, followed by spinal $(9.5 \%)$ and pelvic $(4.5 \%)$ injuries.

Tanaka $e t$ a $l^{18}$ reported that less than $7.5 \%$ of the HanshinAwaji earthquake victims had cranial, thoracic, and abdominal injuries but the mortality among these cases was high $(20.3 \%)$. Our findings were somewhat different. The rate of the cranial, thoracic, and abdominal injuries together was $17 \%$ and the mortality among these patients (17.5\%) ranked second after the crush syndrome.
When non-trauma earthquake victims were considered, $25.4 \%$ presented within the first three days whereas $87.5 \%$ of trauma patients presented in the same time period. Liang et $a l^{20}$ stated that following the 1999 Taiwan earthquake, approximately $10 \%$ of the patients arriving within the first three days had diseases unrelated to trauma. Following the Hanshin-Awaji earthquake, an increase in the number of cases related to stress (such as myocardial infarction, peptic ulcer, etc.) has been reported. ${ }^{18}$ Suzuki et al have also pointed out a remarkable increase in the frequency of the cases of myocardial infarction during the first week following the earthquake in the Awaji region. ${ }^{21}$ Although in our study the total number of non-trauma patients hospitalised was relatively low, acute coronary syndrome was still the most frequent diagnosis. It is widely known that emotional stress causes ischaemic cardiac diseases and acute myocardial infarction, ${ }^{22}$ and, in an event such as an earthquake, which results in incredible pressure on victims, the increase in stress induced illnesses seems inevitable.

In our study, detailed medical records of 58 hospitalised patients were not available. The most important reason for this was the initial disorganisation in the ED especially during the first few hours after the earthquake. Nevertheless, we think that the data reported in the present study reflect sufficient medical information about the morbidity and mortality of the hospitalised post-earthquake trauma and non-trauma patients.

\section{CONCLUSIONS}

Catastrophes can occur anywhere and at any time and the numbers of victims cannot be foreseen in any way. Following a devastating catastrophe such as an earthquake, especially during the initial 24-48 hour period, an excessive flow of patients will always be encountered in EDs resulting in disruption in medical care and interventions. Provision of suitable and sufficient medical care can only be achieved by a well prepared organisation, with management of catastrophic events involving entire units of a hospital.

We had to deal with two major challenges after the 1999 Marmara earthquake. The first was to overcome the initial rush phase and the second was to treat the complications of the crush injuries. We have learnt two lessons from this experience: (a) previous disaster drills would have decreased the initial mortality and morbidity, which was due to disorganised emergency care; and $(b)$ fewer fasciotomies and more conservative treatment of crush injuries would have decreased our late morbidity and mortality, which was due to surgical infections, sepsis and ARF.

\section{Authors' affiliations}

M Bulut, S Akkose, Department of Emergency Medicine, Uludag University Medical School, Bursa, Turkey

R Fedakar, Department of Forensic Medicine, Uludag University Medical School, Bursa, Turkey

S Akgoz, Department of Biostatistics, Uludag University Medical School, Bursa, Turkey

H Ozguc, Department of General Surgery, Uludag University Medical School, Bursa, Turkey

R Tokyay, Department of Emergency Service of American Hospital, Istanbul, Turkey

Competing interests: none declared

\section{REFERENCES}

1 Crisis Center of the Turkish Prime Ministry. Earthquakes 1999. Ankara: Prime Ministry, 2000:3-15.

2 Gans L. Disaster planning and management. In: Harwood Nuss AL, ed. The clinical practice of emergency medicine. Philadelphia: Lippincott-Raven Publishers, 1996:1511-13.

3 Reitherman R. How to prepare a hospital for an earthquake. J Emerg Med 1986;4:119-31. 
4 Mahoney LE, Reutershan TP. Catastrophic disasters and the design of disaster medical care systems. Ann Emerg Med 1987;16:1085-91.

5 Building Seismic Safety Council. Seismic Considerations: Health care facilities. Washington DC: Federal Emergency Management Agency Publication, 1990:FEMA 150.

6 Taviloglu K. 17 Agustos 1999 Marmara depreminin ardından felake organizasyonunda neredeyiz. Ulusal Cerrahi Dergisi 1999;6:333-42.

7 Peak-Asa C, Kraus J F, Bourque LB, et al. Fatal and hospitalised injuries resulting from the 1994 Northridge earthquake. Int J Epidemiol 1998:27:459-65

8 Zhi-Yong S. Medical support in the Tangshan earthquake: a review of the management of mass casualties and certain major injuries. J Trauma 1987;27:1130-4.

9 Yankaver A. Preparing for disaster. Am J Public Health 1986:76:233-5.

10 Kuwagata Y, Oda J, Tanaka H, et al. Analysis of 2702 traumatized patients in the 1995 Hanshin-Awaji earthquake. J Trauma 1997;43:427-32.

11 Haynes BE, Freeman C, Rubin JL, et al. Medical response to catastrophic events: California's planning and the Loma Prieta earthquake. Ann Emerg Med 1992;21:368-74.

12 Martchenke J, Pointer JE. Hospital disaster operations during the 1989 Loma Prieta earthquake. Prehosp Disaster Med 1994;9:146-53.

13 Chen W, Cfreng Y, $\mathrm{Ng} \mathrm{K}$, et al. Were there enough physicians in an emergency department in the affected area after a major earthquake? An analysis of the Taiwan Chi-Chi earthquake in 1999. Ann Emerg Med $2001 ; 38: 556-61$

14 Klein JS, Weigelt JA. Disaster management. Lessons learned. Surg Clin North Am 1991;71:257-66.

15 Tanaka K. The Kobe earthquake: the system response. A disaster report from Japan. Eur J Emerg Med 1996;3:263-9.

16 Collins AJ. Kidney dialysis treatment for victims of the Armenian earthquake. N Engl J Med 1989;320:1291-2.

17 Oda J, Tanaka H, Yoshioka T, et al. Analysis of 372 patients with crush syndrome caused by the Hanshin-Awaji earthquake. J Trauma 1997;42:470-5.

18 Tanaka H, Oda J, Atsushi I, et al. Morbidity and mortality of hospitalised patients after the 1995 Hanshin-Awaji earthquake. Am J Emerg Med 1999; 17:186-91.

19 Pointer JE, Michaelis J, Saunders C, et al. The 1989 Loma Prieta earthquake: Impact on hospital patient care. Ann Emerg Med 1992;21:1228-33.

20 Liang N, Shih Y, Shih F, et al. Disaster epidemiology and medical response in the Chi-Chi earthquake in Taiwan. Ann Emerg Med 2001;38:549-55.

21 Suzuki S, Sakamoto S, Miki T, et al. Hanshin-Awaji earthquake and acute MI. Lancet 1995;345:981.

22 Trichopoulos D, Klea K, Zavitsanos E, et al. Psychological stress and fatal heart attack: the Athens (1981) earthquake natural experiment. Lancet 1983;26:441-3. 